\title{
Development and Validation of Phonetically Balanced Speech Perception Test in Urdu Language
}

Hina Noor

Allama Iqbal Open University, hina.noor@aiou.edu.pk

Manzoor H. Arif

Bilquis College of Education, manzoor.arif@bcoew.edu.pk

Follow this and additional works at: https://nsuworks.nova.edu/ijahsp

Part of the Medicine and Health Sciences Commons

\section{Recommended Citation}

Noor $\mathrm{H}$, Arif $\mathrm{MH}$. Development and Validation of Phonetically Balanced Speech Perception Test in Urdu Language. The Internet Journal of Allied Health Sciences and Practice. 2018 Jan 01;16(4), Article 12.

This Manuscript is brought to you for free and open access by the College of Health Care Sciences at NSUWorks. It has been accepted for inclusion in Internet Journal of Allied Health Sciences and Practice by an authorized editor of NSUWorks. For more information, please contact nsuworks@nova.edu. 


\title{
Development and Validation of Phonetically Balanced Speech Perception Test in Urdu Language
}

\begin{abstract}
Purpose: The tool of speech or language assessment is required to be linguistically and culturally appropriate for the individual being tested. Testing in native language is essential if an audiologist or speech and language therapist wants to test the speech perception capacities of an individual and to use the data for further planning and monitoring of the therapeutic efforts. Numerous speech perception tests are available in different international and regional languages. But in Urdu language, no such tool is available to the clinicians to check the speech perception abilities of hearing impaired individuals. Therefore, this study was designed to: (1) estimating the frequency of occurrence of Urdu consonants; (2) developing a speech perception test in Urdu Language for children with hearing impairment; and (3) establishing the reliability and validity of the test.

Methods: This study was carried out in three stages. In stage I, structural attributes of the test were planned. During stage II, firstly mean phonetic occurrence of each consonant in Urdu language was calculated. Secondly, a pool of most common image-able Urdu words was generated from which a 25 word-list for identification task was created. Finally, the speech perception test was finalized after establishing its content validity. In stage III, reliability and validity of the test was established through a pilot study conducted via randomly selected 100 normally hearing and 30 hearing impaired subjects.
\end{abstract}

Results: The Urdu speech perception test is a non-verbal, norm referenced test. Content, predictive and construct validity was established. Split half reliability of the test was 0.798 and test-retest reliability was 0.881 which was found to be significant at $\alpha=0.05$ and $\alpha=0.01$ level of significance respectively. Interscorer reliability was 0.598 which was significant at $\alpha=0.10$ level.

Conclusions: The Urdu speech perception test is a reliable, validated and linguistically appropriate non verbal tool to check the speech perception abilities of children with hearing impairment.

\section{Author Bio(s)}

1) Hina Noor, Ph.D, is an experienced speech language therapist. She is a lecturer in the Department of Special Education, Room \# 116, Faculty of Education, Allama Iqbal Open University, H-8, Islamabad, Pakistan.

Manzoor Hussain Arif, PhD, is a professor in the Teacher Training Institute, Bilquis College of Education, Rawalpindi, Pakistan.

\section{Acknowledgements}

The work is based on Ph. D study supported by Higher Education Commission, Pakistan under 5000 indigenous scholarship scheme (085-10471-SS5-234). The dissertation was submitted to HEC on Sep 2015. The work is not published elsewhere except that it was presented as poster presentation in IRSC 2017, Feb 25-26. 


\title{
TIVAHSP \\ The Internet Jous?nal of Allied Health Sciences and Practice
}

Dedicated to allied health professional practice and education

Vol. 16 No. 4 ISSN 1540-580X

\section{Development and Validation of Phonetically Balanced Speech Perception Test in Urdu Language}

\author{
Hina Noor, SLT ${ }^{1}$ \\ Manzoor Hussain Arif, PhD 2 \\ 1. Allama Iqbal Open University \\ 2. Bilqees College of Education \\ Pakistan
}

\begin{abstract}
Purpose: The tool of speech or language assessment is required to be linguistically and culturally appropriate for the individual being tested. Testing in native language is essential if an audiologist or speech and language therapist wants to test the speech perception capacities of an individual and to use the data for further planning and monitoring of the therapeutic efforts. Numerous speech perception tests are available in different international and regional languages. But in Urdu language, no such tool is available to the clinicians to check the speech perception abilities of hearing impaired individuals. Therefore, this study was designed to: (1) estimate the frequency of occurrence of Urdu consonants; (2) develop a speech perception test in Urdu language for children with hearing impairments; and 3) establish the reliability and validity of the test. Methods: This study was carried out in three stages. In stage I, structural attributes of the test were planned. During stage II, mean phonetic occurrence of each consonant in Urdu language was calculated. Then a pool of the most common image-able Urdu words was generated from which a 25 word-list for identification task was created. Finally, the speech perception test was finalized after establishing its content validity. In stage III, reliability and validity of the test was established through a pilot study conducted via randomly selected 100 normally hearing and 30 hearing impaired subjects. Results: The Urdu speech perception test is a non-verbal, norm referenced test. Content, predictive and construct validity was established. Split half reliability of the test was 0.798 and test-retest reliability was 0.881 which was found to be significant at $\alpha=0.05$ and 0.01 level of significance. Inter-scorer reliability was 0.598 which was significant at $\alpha=0.10$ level. Conclusions: The Urdu speech perception test is a reliable, validated and linguistically appropriate non verbal tool to check the speech perception abilities of children with hearing impairment.
\end{abstract}

Keywords: hearing impairment, phonetic balance speech perception test, Urdu language. 


\section{INTRODUCTION}

Speech perception refers to how an individual understands what is heard by the person. It is a skill that helps us to differentiate between the sounds, words, and syllables spoken by the speaker. The impact of hearing loss on an individual depends on the extent to which a person's speech perception is affected. The improvement in speech perception is considered as a primary goal of management of individuals with hearing impairment. Speech perception testing is not only used to provide information about the individual's speech perception ability but is also used for effective selection, planning, implementation, and evaluation of the rehabilitation process. ${ }^{1}$ The speech language pathology and audiology professionals have tools to identify hearing loss at birth and to fit sensory devices soon thereafter. However, professionals are limited in age appropriate behavioural tests required to assess auditory perceptual performance. ${ }^{2}$ Without testing, professionals cannot accurately know what the person can and cannot hear.

Different kinds of materials have been developed by investigators, but speech testing material needs to be linguistically appropriate for the person being tested. Moreover, factors like the age, cognitive level, level of complexity of material, and competing noises present in the environment should be given due importance. ${ }^{3,4}$ The work of researchers have supported that the accuracy of test results depends upon familiarity or subject's knowledge of the test material. Testing in non-native language may yield an inaccurate low score. ${ }^{5}$ It is difficult and inappropriate to assess primary speech perception ability in English when a person's native language is not English. For example, several speech tests have been developed in other languages including Mandarin Chinese, Russian, Arabic, and the llocano PB word recognition test.6-9 Standardized speech audiometric materials and tests in different Indian regional languages have also been developed, such as Konkani, Marathi, PB word list in Telugu. ${ }^{10-12} \mathrm{~A}$ review of literature by the co-authors did not find any speech perception test developed in Urdu Language.

Urdu, the national language of Pakistan, is spoken by more than 10 million people in Pakistan and 60,290,000 people in the world. ${ }^{13}$ The books on Urdu literature and grammar are available. But little research has been done on its acoustic properties, and resources available for research in Urdu language are also limited..$^{14}$ The main criteria for selecting a material of any speech test is the phonemic structure of the language. ${ }^{15}$ In Urdu language phonemes, there is still a controversy regarding the total number of consonants (i.e. 36, 37 and 42 consonants). ${ }^{16}$ The notion of using a phonetically balanced word list for the word recognition test is not new, and many phonetically balanced word lists have already been developed in different languages, as mentioned earlier. Previous reports by researchers have commented that the notion of arriving at any phonetically balanced word list in its true sense is impossible as the frequency of occurrence of phonemes may vary with the change in the topic. ${ }^{17}$ The estimation of at-least most frequently occurring phoneme may satisfy the tester with the assumption that the individual is exposed to the most frequently occurring material for testing. Keeping in view the little research done on phonemic characteristics of Urdu language and the trend of using phonetically balanced word-list in speech testing, the current study has three primary aims: I) to estimate the frequency of occurrence of Urdu consonants in spoken language; II) to develop a phonetically balanced speech perception test for children with hearing impairment; and III) to establish reliability and validity of the test.

\section{METHODS}

The study was carried out in three different stages: determining the conceptual framework of the test, developing the test, and finally pilot testing the test.

\section{Stage I: Determination of the Structure of the Test}

The test included four separate sections to check the four listening sub skills of the children. ${ }^{18}$ The four skills were detection, discrimination, identification, and comprehension. It was planned to check the detection of environmental sounds and isolated phonemes of Urdu language. Skills of gross discrimination based on supra-segmental differences and fine discrimination based on consonantal differences were checked separately. The study involved the creation of a phonetically balanced word list for the task of identification having mono and bi-syllabic words. For the comprehension section, it was planned to ask some general and personal questions from the respondents to estimate their comprehension capabilities.

\section{Stage II: Development of a Phonetically Balanced Urdu Speech Perception Test}

The stage of development of the test was further sub-divided into four phases: 1) estimation of the frequency of occurrence of consonants in spoken Urdu language, 2) the familiarity check of image-able Urdu words,3) preparation of the phonetically balanced word list for identification section of the test, and 4) finalization of the contents of the test and content validation. 
The estimation of the frequency of occurrence of consonants in spoken Urdu language

To develop the phonetically balanced speech perception test, the frequency of occurrence of each Urdu consonant was estimated. Consonant analysis by Raza was based on phonemic principles -- the way that a phoneme should be spoken in a word, so it was not used by the researcher. ${ }^{19}$ The focus of the current study was on the acoustic characteristics of speech and thus phonetic occurrence. The way phonemes are actually uttered by the speakers was used. For this purpose, three speech samples of 15 minutes each were recorded by the researcher and/or participant teacher. The recordings were made with the help of an audio recorder on a mobile phone after taking informed consent of the participants.

a) Sample A consisted of 10 short spoken extracts of 1 to 2 minute spoken by 3 to 4 adult speakers with varying age range and gender. These spoken speech samples were recorded by the researcher for five consecutive days as conveniently found in the surroundings. The timings for the recording of the speech samples were randomly selected i.e. 11:00 am and 6:00 pm. The obtained speech sample consisted of up to 670 words in total.

b) Sample B was recorded by a volunteer playgroup teacher of a local mainstream school after getting permission from the head of the school. Recording was done when children were freely talking with each other as well as with the teacher in the class room. As a result, a speech sample of 680 words was obtained.

c) Sample $\mathrm{C}$ of 800 words was a recorded conversation between parents, teachers, and children at a parent-teaching meeting in the same local school. After getting the consent of the teacher and the parents, the recording was done by the researcher while participating in the conversation.

All audio speech samples were played back and transcribed for further analysis in order to calculate the frequency of occurrence of each Urdu consonant in words. A list of 26 Urdu consonants was prepared in which the aspirated Urdu consonants were taken jointly with their phone and $/ \mathrm{k} /$ was taken with $/ \mathrm{q} /$. Tallies were made against the list of consonants for each recorded and transcribed sample. The mean occurrence of each consonant was calculated by using the total occurrence of each consonant in all three sample divided by three. Finally, the weighted mean occurrence for the 25 word-list of all these Urdu consonants was calculated with the help of formula, $X^{-} \times 25 / 716$, where 716 is the average number of words calculated for three spoken samples.

\section{The familiarity check of image-able Urdu words}

A pool of familiar Urdu words was created for the selection of words for the identification task of the test. For this purpose, a list of image-able words was created by choosing vocabulary words from five randomly selected Urdu readers for toddlers. Common nouns belonging to the categories of body parts, fruits, vegetables, animals, and birds were chosen from the books. A few action words, pronouns, adjectives, and counting from one to ten were also added in the list. As a result, a list of 168 image-able words was obtained and arranged alphabetically.

A three-point Likert scale questionnaire was developed to rate the familiarity of these words from very familiar to not familiar word. Twenty five native Urdu speakers of age range 35 to 45 years were selected by snowball sampling technique to rate the familiarity of these words. It was ensured that all selected native speakers belonged to the different districts of Punjab. All words that were rated as not familiar by these native speakers were excluded from the list. Finally, the pool of image-able Urdu word list consisted of 136 words. From the pool, 25 words were required to be selected for the identification task.

Preparation of the phonetically balanced word list for identification section of the test

For the identification task, a list of 25 words was prepared from the pool of common image-able Urdu words. It contained 12 monosyllabic and 13 bi-syllabic words. It was ensured while choosing the words from the pool that the target word list has exactly the same weighted occurrence of each Urdu consonant as calculated earlier in phase 2. Although the practice of equating the frequency of occurrence of consonants with the calculated frequency is not common, it was done to ensure the presence of consonants with the same frequency and proportion as found in everyday life. $8,9,12,15$

Finalization of the contents of the test and content validation.

A questionnaire for the audiologists, speech language therapists, and Urdu Language experts was prepared to check the content validity of the proposed test. Three professionals of each mentioned category of experts were contacted to comment on the appropriateness of the task and relevance of each item with the task. It was recommended by the professionals to exclude the non-speech sounds from the detection section of the test. A revision in the comprehension section was also made by changing everyday sentences with the sentences based on information carrying words, in the light of expert opinion. As a result of the changes, all four sections of the test were requiring only the non-verbal responses from the respondents. After incorporating the 
recommendations of the professionals, the Urdu speech perception test (USPT) was finalized as a non verbal test. The nonverbal response method may help the clinicians to take the test of individuals with limited expressive language skills.

The USPT consisted of four sections: detection, discrimination, identification, and comprehension of the speech stimuli. The detection section was limited to the detection of low and high frequency isolated phonemes, selected on the basis of most frequently occurring sounds. There were three vowels and seven Urdu consonants covering the low and high frequency area of speech banana. The respondent was simply required to raise his or her hand on the reception of any sound stimuli. Both gross and fine discrimination skill assessed by the discrimination section of the test. The 10 items of gross discrimination were selected on the basis of stress, intonation, and duration differences. The respondent was required to indicate nonverbally that the two sound stimuli were the "same" or "different." The fine discrimination section consisted of 10 paired items, selected on the basis of minimal perceptual differences (i.e. having the same phonic and supra-segmental features and differing only in one consonant). There were seven mono-syllabic paired words and three bi or tri-syllabic paired words in the list. The respondent was required to indicate non-verbally which of the three stimuli is different from others -- first, second, or third. The 25 word-list for the identification task was having 12 monosyllabic and 13 bi-syllabic words. The respondents were required to point to the picture of the word spoken by the tester. For the comprehension task, five sentences were generated on the basis of 1 to 4 information carrying words. The respondents were required to choose and show the item(s) as asked by the tester. Each item of the test carries one mark; hence, it is a test with 60 total marks. All of the above delineated structural attributes of the USPT are summarized in Table 1.

Table 1: Structural attributes of Urdu speech perception test, showing the detail of four levels of listening. All four skills are depicted in the context of their linguistics properties, acoustics contents, required response type and item details.

\begin{tabular}{|c|c|c|c|c|c|}
\hline Content & Detection & \multicolumn{2}{|c|}{ Discrimination } & Identification & Comprehensio \\
\hline Linguistics & $\begin{array}{l}\text { Sounds in } \\
\text { isolation }\end{array}$ & $\begin{array}{l}\text { Supra segmental, vowels } \\
\text { in mono, bi and tri- } \\
\text { syllabic words }\end{array}$ & $\begin{array}{l}\text { Consonants in } \\
\text { mono and bi- } \\
\text { syllabic words }\end{array}$ & $\begin{array}{l}\text { Mono and bi } \\
\text { syllabic words }\end{array}$ & $\begin{array}{l}\text { Questions } \\
\text { carrying up-to } 4 \\
\text { information } \\
\text { carrying words }\end{array}$ \\
\hline $\begin{array}{l}\text { Phonetic } \\
\text { Balance }\end{array}$ & No & No & No & Yes & No \\
\hline Acoustics & $\begin{array}{l}\text { Vowels and } \\
\text { consonants }\end{array}$ & $\begin{array}{l}\text { Vowel versus vowel, } \\
\text { Vowel versus word, } \\
\text { Mono versus mono and } \\
\text { bi-syllabic words. Tri } \\
\text { versus tri and bi-syllabic } \\
\text { words differing only in } \\
\text { vowels. }\end{array}$ & $\begin{array}{l}\text { Words differing } \\
\text { only in } \\
\text { consonants at all } \\
\text { positions in words }\end{array}$ & Words in isolation & $\begin{array}{l}\text { Speech with } \\
\text { natural } \\
\text { intonation }\end{array}$ \\
\hline \multicolumn{6}{|l|}{ Response } \\
\hline Set & $\begin{array}{l}\text { Closed 2- } \\
\text { choice }\end{array}$ & Closed 2-choice & Closed 3-choice & Closed choice & Closed choice \\
\hline Method & $\begin{array}{l}\text { Yes/no } \\
\text { response }\end{array}$ & $\begin{array}{l}\text { Same/ different } \\
\text { response }\end{array}$ & $\begin{array}{l}\text { Pick the add one } \\
\text { out }\end{array}$ & Point to the picture & $\begin{array}{l}\text { Choose from the } \\
\text { given objects } \\
\text { and follow } \\
\text { command }\end{array}$ \\
\hline $\begin{array}{l}\text { Number of } \\
\text { items per list }\end{array}$ & 10 & 10 & 10 & $12+13=25$ & 5 Sentences \\
\hline Number of list & 1 & 1 & 1 & 1 & 1 \\
\hline
\end{tabular}

\section{STAGE III: Validation of the Test}

A pilot study was conducted for the purpose of establishing reliability and validity of the USPT.

Selection of the subjects for the pilot test

First of all, a few nearby institutes were selected on the basis of convenience of the researcher. A letter of interest was delivered to them explaining the researcher's intent and expected benefits of the study. After seeking the permission from the head of the institute, the requirements and method of testing children enrolled in their school were explained to the authorities. A note on the 
school diaries of the children between 4 to 14 years of age was written to obtain consent of the parents. One hundred normally hearing subjects from a local mainstreamed co-education school were randomly selected for speech perception testing. Ten subjects were randomly selected from each age group from 4 to 14 years age range. Selected subjects from each age group were having equal representation of both genders. Similarly, 30 hearing impaired subjects were randomly selected from a local special education institute for individuals with hearing impairment. It was ensured that two profoundly impaired subjects and one severely profound subject using bilateral digital hearing aid was included in each age group.

Administration of the test

Two volunteers were selected to work with the researcher for collecting speech perception scores of normally hearing as well as hearing impaired subjects. Two testers (the researcher and one of the volunteers) decided to take the test of the selected subjects during school hours. The volunteers were given orientation to the purpose and procedure of testing and provided with the written guidelines. The first 10 tests by volunteers were also monitored by the researcher for any discrepancy in the procedure of testing. The live voice of the volunteers was also monitored for uniformity. All sound stimuli were presented only once, in a closed room of the institute. The distance between the tester and subject was 8 to 10 feet. Data analysis was done to establish construct as well as predictive validity, split half, test- retest and inter-scorer reliability.

\section{RESULTS}

The number of Urdu consonants included in the list was 44 . $/$ / was omitted because of its deletion pattern found in speech samples of native Urdu speakers. The 44 consonants and the omitted one thus make a total of 45 consonants. These 45 consonants are the same as mentioned in Urdu phonetic inventory published by Centre for Language Engineering. ${ }^{16}$ It was noted during the consonant analysis of the Urdu speech samples that

1. The phoneme $/ \mathrm{h} /$ at the middle and especially at the final position tended to be omitted or replaced by a vowel or diphthong by the speakers.

2. The phoneme $/ 3 /$ mostly tended to be substituted by a diphthong by Pakistani Urdu speakers in everyday life.

3. The high frequency of the phonemes like $/ \mathrm{k} /, / \mathrm{Vl}, / \mathrm{s} /, / \mathrm{h} /, / \mathrm{m} /, / \mathrm{n} /, / \mathrm{r} /$ etc was due to the presence of excessive functional words in every day Urdu speech.

4. Frequency of $/ r /$ was the highest at the final position among three positions in words.

5. The phenomenon of language code switching was prevailing because various English words (e.g. car, gate, pen) were being used by the native speakers in their every day routine instead of the Urdu vocabulary words for these concepts.

The tallies made in each category of consonant in each sample were used to estimate the frequency of occurrence of the consonants of Urdu language. Mean frequency of occurrence of each Urdu consonant was calculated by using the formula, $\mathrm{X}^{-}=$ $\Sigma X / n$. Then the weighted frequency of occurrence of each consonant was calculated by using the formula, $X^{-} \times 25 / N$. Here $N$ stands for the average number of total words of all three speech samples. The summary of the frequency of occurrence of consonants along with their aspirated sounds in the spoken speech sample, their mean frequency, and weighted frequency in 25 word-list is given in the Table 2 .

Table 2: The mean frequency of occurrence of Urdu consonants in recorded speech samples and finally estimated in 25 word-list with the help of weighted average formula

\begin{tabular}{|c|c|c|c|c|c|c|}
\hline & $\begin{array}{l}\text { Sounds (IPA } \\
\text { symbols) }\end{array}$ & Sample A & Sample B & Sample C & $\begin{array}{l}\text { Mean } \\
\text { occurrence } \\
\left(\mathrm{X}^{-}\right)\end{array}$ & $\begin{array}{l}\text { Occurrence } \\
\text { In 25 word } \\
\text { list (A) }\end{array}$ \\
\hline 1. & $/ \mathrm{p} /+\mathrm{p}^{\mathrm{h}}$ & 34 & 41 & 54 & 43 & 1.50 \\
\hline 2. & $/ \mathrm{b} / \mathrm{b}^{\mathrm{h}}$ & 37 & 56 & 62 & 52 & 1.80 \\
\hline 3. & $/ \mathrm{t} / \mathrm{t}^{\mathrm{h}}$ & 16 & 58 & 58 & 44 & 1.53 \\
\hline 4. & $/ \mathrm{d} /+\mathrm{d}^{\mathrm{h}}$ & 16 & 14 & 18 & 16 & 0.55 \\
\hline 5. & $/ \mathrm{k} / \mathrm{k}^{\mathrm{h}}+\mathrm{q}$ & 95 & 133 & 179 & 135 & 4.71 \\
\hline 6. & $/ \mathrm{g} /+\mathrm{g}^{\mathrm{h}}$ & 35 & 65 & 48 & 49 & 1.71 \\
\hline 7. & $/ \mathrm{f} /$ & 12 & 39 & 35 & 29 & 1.01 \\
\hline 8. & $/ \mathrm{v} /$ & 89 & 72 & 126 & 96 & 3.35 \\
\hline 9. & $/ \mathrm{t}+\mathrm{t}^{\mathrm{h}}$ & 3 & 4 & 21 & 9 & 0.31 \\
\hline 10. & $/ \mathrm{d} /+\mathrm{d}^{\mathrm{h}}$ & 35 & 32 & 50 & 39 & 1.36 \\
\hline 11. & $/ \mathrm{s} /$ & 58 & 69 & 94 & 73 & 2.54 \\
\hline
\end{tabular}




\begin{tabular}{|c|c|c|c|c|c|c|}
\hline 12. & $|z|$ & 6 & 21 & 19 & 15 & 0.52 \\
\hline 13. & $1 \sqrt{1}$ & 7 & 8 & 36 & 17 & 0.59 \\
\hline 14. & $\mid 3 /+j_{+} j h$ & 39 & 63 & 32 & 45 & 1.57 \\
\hline 15. & $/ \mathrm{h} /$ & 129 & 105 & 171 & 135 & 4.71 \\
\hline 16. & $/ \mathrm{m} /+\mathrm{m}^{\mathrm{h}}$ & 74 & 49 & 74 & 67 & 2.33 \\
\hline 17. & $\ln /+n h$ & 87 & 69 & 100 & 85 & 2.96 \\
\hline 18. & $\ln /$ & 1 & 3 & 4 & 2 & 0 \\
\hline 19. & $t+1+t g^{h}$ & 16 & 20 & 35 & 24 & 0.83 \\
\hline 20. & $/ d \sqrt{3} /+d 3 h$ & 27 & 19 & 28 & 25 & 0.87 \\
\hline 21. & $\mathrm{~N} / \mathrm{+} \mathrm{h}$ & 59 & 46 & 62 & 56 & 1.95 \\
\hline 22. & $\mid r /+r h$ & 91 & 137 & 121 & 116 & 4.05 \\
\hline 23. & $|x|$ & 5 & 3 & 5 & 4 & 0 \\
\hline 24. & 181 & 7 & 0 & 1 & 3 & 0 \\
\hline 25. & $\pi+r^{h}$ & 7 & 8 & 5 & 7 & 0.24 \\
\hline
\end{tabular}

The presentation of frequently occurring consonants of the Urdu language is better projected with the help of the Figure 1. The graphic representation of the frequency of occurrence of Urdu consonants makes it evident that the consonants with highest frequency were voiceless i.e. $/ \mathrm{k} /, / \mathrm{h} /$ and $/ \mathrm{r} /$. Next were the voiced consonants $/ \mathrm{v} /, / \mathrm{m} /, / \mathrm{n} /$ with the exception of a voice less $/ \mathrm{s} /$.

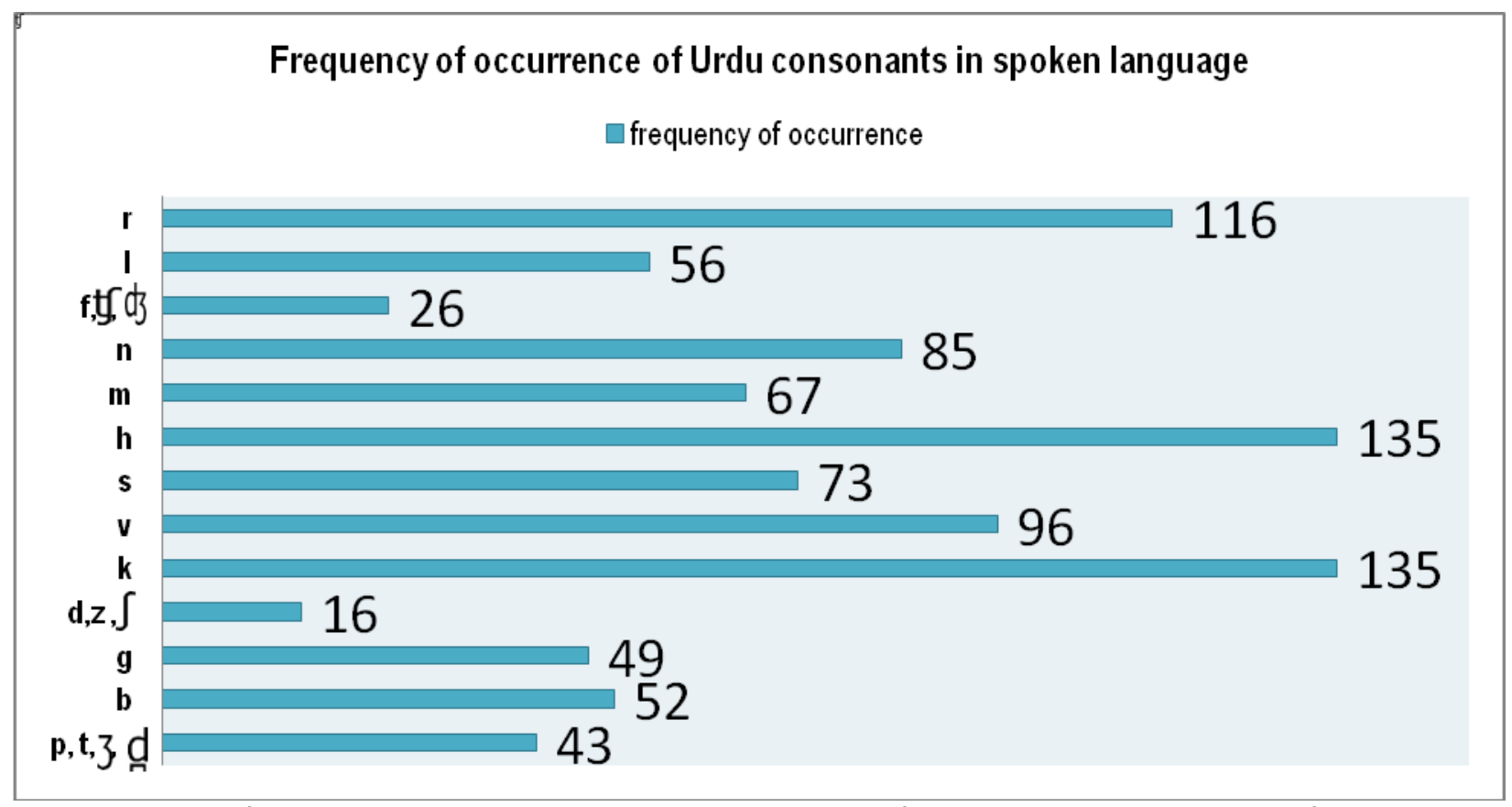

Figure 1: The most frequently occurring consonants that should be given preference in auditory training lessons for the children with hearing impairment

For standardization, raw scores of normally hearing as well as hearing impaired subjects were converted into standard scores and percentile ranks. For this purpose, the raw scores obtained by the normally hearing subjects as well as the subjects with hearing impairment were tabulated against their frequency distribution first and then converted into percentile ranks and standard scores. Frequency distribution of the speech perception raw scores, percentile ranks and z scores obtained by 100 normally hearing subjects is depicted in the table 3 . The same measures for subjects with hearing impairment are provided in the table 4. 
Table 3: The Speech perception raw scores of 100 normally hearing subjects, their percentile ranks and $\mathbf{z}$ scores

\begin{tabular}{|l|l|l|l|l|}
\hline $\begin{array}{l}\text { Raw scores out of } \\
\text { total score of } 60\end{array}$ & $\begin{array}{l}\text { Frequency of the raw } \\
\text { score by the } \\
\text { volunteer }\end{array}$ & $\begin{array}{l}\text { Frequency of the raw } \\
\text { score by the } \\
\text { researcher }\end{array}$ & $\begin{array}{l}\text { Percentile ranks } \\
p 2=2\left(\frac{n+1}{100}\right)^{\text {th }} \\
\text { Value of array }\end{array}$ & $\begin{array}{l}\text { Standard score } \\
\mathrm{z}=\mathrm{X}-\mathrm{X}^{-} / \mathrm{S} . \mathrm{D}\end{array}$ \\
\hline 45 & 0 & 1 & $0.01^{\text {th }}$ & 27.4 \\
\hline 46 & 0 & 0 & $1.01^{\text {th }}$ & 30.37 \\
\hline 47 & 0 & 0 & $1.01^{\text {th }}$ & 33.39 \\
\hline 48 & 0 & 3 & $3.03^{\text {th }}$ & 36.41 \\
\hline 49 & 3 & 2 & $4.04^{\text {th }}$ & 39.43 \\
\hline 50 & 1 & 0 & $9.09^{\text {th }}$ & 42.45 \\
\hline 51 & 1 & 1 & $10.10^{\text {th }}$ & 45.47 \\
\hline 52 & 4 & 1 & $12.12^{\text {th }}$ & 48.49 \\
\hline 53 & 6 & 5 & $1616^{\text {th }}$ & 51.51 \\
\hline 54 & 1 & 1 & $29.29^{\text {th }}$ & 54.53 \\
\hline 55 & 4 & 4 & $37.37^{\text {th }}$ & 57.55 \\
\hline 56 & 7 & 11 & $55.55^{\text {th }}$ & 60.57 \\
\hline 57 & 5 & 7 & $67.67^{\text {th }}$ & 63.59 \\
\hline 58 & 9 & 6 & $82.82^{\text {th }}$ & 66.61 \\
\hline 59 & 5 & 5 & $92.92^{\text {th }}$ & 69.63 \\
\hline 60 & 4 & 3 & $99.99^{\text {th }}$ & 72.65 \\
\hline
\end{tabular}

Table 4: The Speech perception raw scores of 30 subjects with hearing impairment, their percentile ranks and $z$ scores

\begin{tabular}{|c|c|c|c|}
\hline Raw scores out of 60 & Frequency of the scores & Percentile ranks & Standard score \\
\hline 0 & 3 & 1 st & 38.30 \\
\hline 2 & 1 & $3^{\text {rd }}$ & 40.10 \\
\hline 3 & 2 & $16^{\text {th }}$ & 41.009 \\
\hline 4 & 1 & $23^{\text {rd }}$ & 41.91 \\
\hline 5 & 2 & $26^{\text {th }}$ & 42.81 \\
\hline 6 & 1 & $32^{\text {th }}$ & 43.71 \\
\hline 7 & 1 & $36^{\text {th }}$ & 44.61 \\
\hline 9 & 1 & $39^{\text {th }}$ & 46.42 \\
\hline 10 & 1 & $42^{\text {nd }}$ & 47.32 \\
\hline 11 & 4 & $46^{\text {th }}$ & 48.23 \\
\hline 12 & 2 & $60^{\text {th }}$ & 49.13 \\
\hline 13 & 1 & $64^{\text {th }}$ & 50.03 \\
\hline 16 & 2 & $68^{\text {th }}$ & 52.74 \\
\hline 17 & 1 & $75^{\text {th }}$ & 53.64 \\
\hline 19 & 1 & $78^{\text {th }}$ & 55.45 \\
\hline 24 & 2 & $81^{\text {st }}$ & 59.96 \\
\hline 25 & 1 & $87^{\text {th }}$ & 60.86 \\
\hline 29 & 1 & $91^{\text {st }}$ & 64.47 \\
\hline 42 & 2 & $94^{\text {th }}$ & 76.21 \\
\hline
\end{tabular}

The mean speech perception scores of normally hearing as well as hearing impaired subjects were calculated for each age group. Each age group was of one year age from 4 to 14 years thus forming the 10 groups of age range. These mean scores were used to get the evidence of predictive and construct validity of Urdu Speech Perception Test.

\section{Predictive Validity}

The mean scores of normally hearing as well as hearing impaired subjects were calculated for each age group from 4 to 14 years age range and plotted together in the form of bar chart. This bar chart shown in Figure 2 gave the evidence of the predictive validity of the USPT as the mean scores of subjects with hearing impairment in each age group were far below the scores of normally 
hearing subjects. Moreover there was also the striking difference in the scores of subjects with severe and profound impairment. Thus the subjects predicted to differ in test performance actually did so.

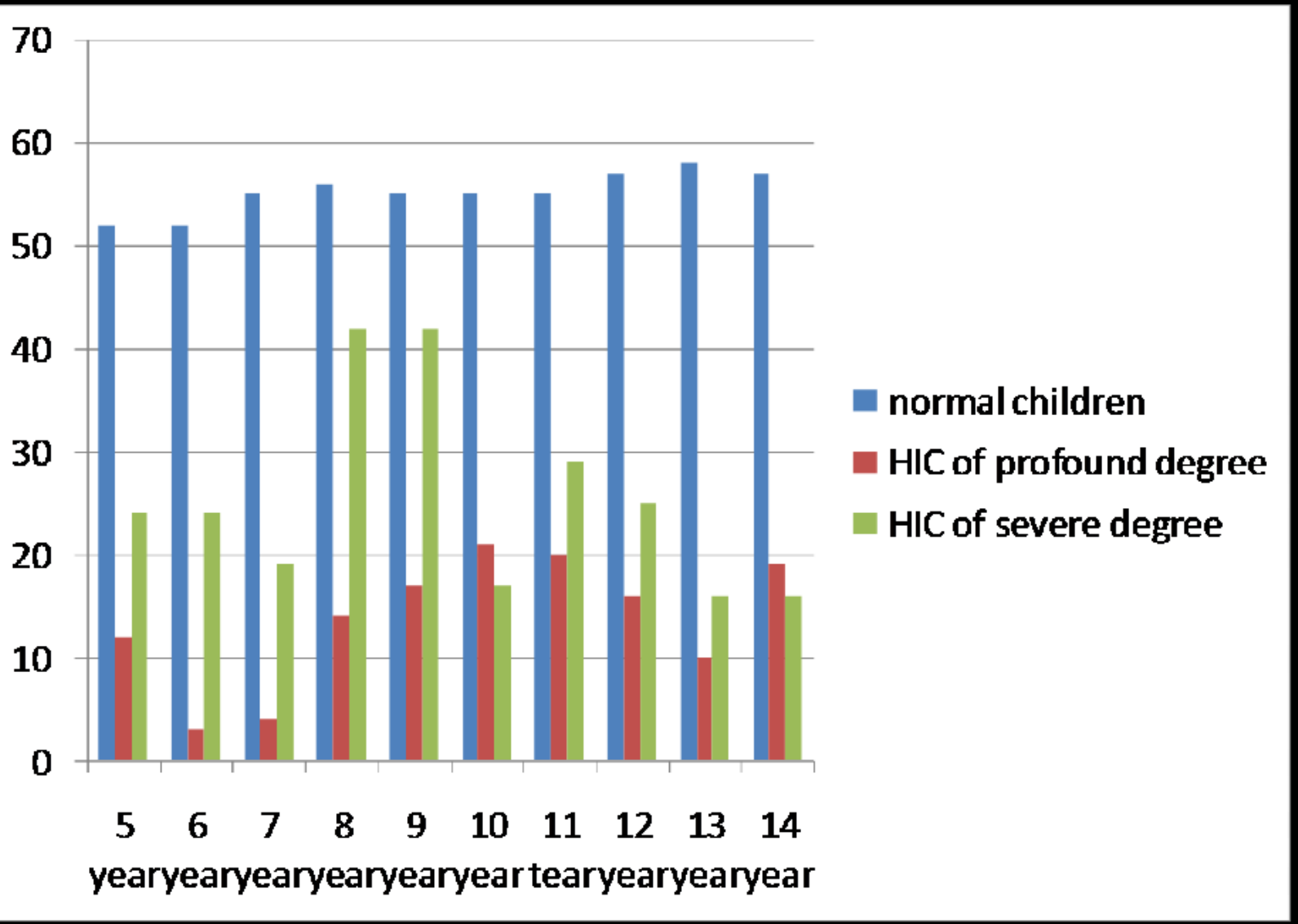

Figure 2. Mean scores of normally hearing and hearing impaired subjects

\section{Construct Validity}

The line graph was plotted against the mean scores of normally hearing subjects in each age group to get insight about the pattern of scores. The slope of line graph showed slow but gradual increase. The line graph shown in Figure 3 gave the evidence of construct validity of the test i.e. scores of the subjects in each age group improved with the increase in age of the subjects.
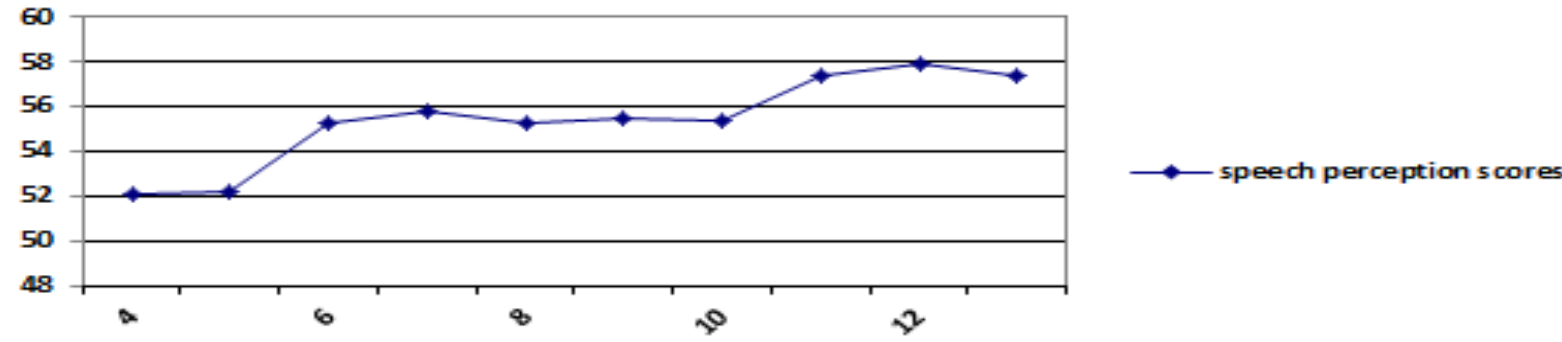

Age (Years)

$\begin{array}{lll}4 & 5 & 6\end{array}$

Mean speech perception scores

$\begin{array}{lll}52.1 & 52.2 & 55.22\end{array}$

$\begin{array}{ll}7 & 8\end{array}$

9

$\begin{array}{llll}9 & 10 & 11 & 12\end{array}$

13

Figure 3. Evidence of construct validity 


\section{Split Half Reliability}

The correlation of the scores of even and odd numbered items was 0.662. The correlation coefficient using Spearman's Brown prophecy was 0.798 , which is quite high. A t-test to check the significance of the relationship at $\alpha=.05$ with $n-2$ degrees of freedom was 3.745 which fell in the critical region. Thus there was enough evidence to support the claim that there is a significant positive correlation between the split half scores of the speech perception test.

\section{Test-retest Reliability}

A retest of ten randomly selected subjects after the interval of 3 months was taken. The gap between tests is assumed to be appropriate as the differences in speech perception skills are not likely to occur in three months duration. The correlation between test-retest scores of ten children was found to be 0.881 . A t-test was administrated and the correlation between scores was significant at $\alpha=.05, \alpha=.02$, and $\alpha=.01$ with $n-2$ degrees of freedom.

Inter-scorer Reliability It inter-scorer reliability was calculated using scores of the same ten children tested by both testers. Spearman's formula was used to calculate the correlation which was found to be 0.0598 , indicating a moderate correlation. The significance of the correlation was checked by applying a t-test which was found to be significant at 0.10 level, but not at 0.05 level. This moderate level of reliability indicated the need of strengthening the instruction manual to be used by the tester. Moreover, the use of recorded sound stimuli was indicated and planned for further study.

\section{DISCUSSION}

First of all, the phenomenon of phonetic balance of Urdu language is discussed. Considering that English phonetically balanced words are mono-syllabic, it was planned to do the analysis of only monosyllabic words. But at the initial stage of data analysis when 700 mono syllabic words were extracted from 1200 words, it was revealed that $80 \%$ of these words were functional words having no meaning independently. Personally, the researchers did not consider it justifiable to ignore the main content words of the language during analysis. The review of test developed in different regional languages revealed that they have not preferred mono syllabic words. ${ }^{9}, 12$ So, it was decided to take all speech samples as a whole having combination of mono, bi, tri, and multi syllabic words. As a whole speech sample was taken, it was cumbersome and a challenge for the researcher to do the vowel analysis in addition to consonant analysis. A detailed analysis of acoustic and phonemic characteristics of all Urdu phonemes may help in further standardization of the tool.

As far as the total number of Urdu consonants is concerned, there were 45 Urdu consonants, but the frequency of occurrence was estimated against 26 items only. It was done to have a cumulative effect of the phoneme by adding the allophones. The number was reduced by taking the aspirated and non aspirated sounds jointly, adding $/ q /$ with $/ \mathrm{k} /$, and totally ignoring $/ \mathrm{P} /$ as the speakers tend to pronounce it as a vowel instead of consonant.

The following deletion rules as observed and mentioned by the researcher are in line with the previous research..$^{20}$

- Deletion of $/ \mathrm{h} /$ at the phonemic boundary

- Deletion of the glottal stop/?/

- Deletion of $/ \mathrm{n} /$ and nasalization of vowel

- Deletion of aspiration

- In phonemic inventory, /q/ exist, but is mapped into / $/$ by Urdu speakers

The deletion rule for $/ \mathrm{h} /$ and $/ \mathrm{j} /$ is further supported by another recent study. ${ }^{21}$

The frequency of Urdu alphabets, calculated by Khan et al was of no use to the researcher as they were based on Urdu alphabets. The 10 alphabets with the highest frequency in Khan's study were $/ \mathrm{r} /, / \mathrm{nl}, / \mathrm{IV} / . / \mathrm{m} /, / \mathrm{t} /, / \mathrm{Il}, / \mathrm{s} /, / \mathrm{d} /, / \mathrm{kl} /, / \mathrm{b} /$ and the ten phonemes with the highest frequency in current study are $/ \mathrm{rl}, / \mathrm{h} /, / \mathrm{lv}, / \mathrm{m} /, / \mathrm{Il}, / \mathrm{s} /, / \mathrm{k} /, / \mathrm{b} /, / \mathrm{g} /, / \mathrm{h} /$. Therefore, eight sounds matches in terms of their frequency of occurence in every day speech. 22 Information about the most frequently occuring consonants and deletion rules may influence the speech and hearing clinicians in determining their assessment and therapeutic goals.

The procedure of exploring the phonetic description of llocano language, finding the commonness of words, and finally the construction of word-list matches with the methodology of the current study. But the procedure to get a phonetically balanced word-list is different. ${ }^{9}$ In order to make a list of the phonetically balanced word list for identification task, the researcher chose only those words from the pool of familiar image-able words that fulfill a specific condition. The condition was that the total frequency of occurrence of the consonants in the full list would be approximately equivalent to the weighted frequency calculated in phase 2 of stage 2 . As a result, the list for the identification task was not only had the most frequently occurring consonants 
but also had the same proportion of the consonants (e.g. / $/ \mathrm{k} /$ is five times and $/ \mathrm{r} /$ is four times present in the list). The treatment satisfied the basic assumption of benefit obtained from phonetically balanced test material that the subjects were exposed to and reflected the same proportion as found in everyday life. Extensive work on the phonemic characteristics of Urdu language may strengthen the future research in the area of tool development in national and regional languages.

As far as the selection of words for the test is concerned, the phenomenon of core vocabulary of any language is very important. Mukati has developed the Urdu core vocabulary of 976 words drawn from 10,301 words. Comparison of the core vocabulary with the pool of familiar words revealed that the selected image-able words were not present in the core vocabulary. Still, the weightage of noun, verb, and adjective in the core vocabulary corresponds with the researcher's selection of words. ${ }^{23}$ Similarly, the comparison between the list of medium vocabulary Urdu isolated words developed by Ali et al and the pool of most familiar words of the current study was made. It was revealed that only counting from one to ten, few nouns, pronouns, and adjectives were the same. The rest of words were different. This difference was due to the presence of more abstract nouns in the list by Ali rather than the concrete image-able nouns of the current study. ${ }^{24}$ The use of image-able words was a pre-requisite when response mode for non-verbal identification task was "point to the picture."

The content pattern of the Urdu speech perception test is also in line with Speech Perception Instructional Curriculum and Evaluation (SPICE). SPICE is an auditory training curriculum that can help the speech language pathologists to evaluate the student's speech perception abilities, plan auditory skills instruction, measure and record student progress, and report to parents and other professionals. Only the word identification segment of USPT is different from SPICE. ${ }^{25}$

Psychometric review of language tests for preschool children revealed that a test is considered norm referenced if it describes the detail of normative samples, test norms showing mean and standard deviation and derived scores like standard scores, percentile ranks etc., in addition to establishing its validity and reliability. USPT is an attempt to be in line with the criteria delineated in the review and is thus may be considered as a norm referenced test. ${ }^{26}$

For establishing reliability and validity of the USPT, a pilot study was conducted with 130 subjects. The study may be replicated by increasing the number of both normally hearing children and hearing impaired subjects. The standard scores and percentile ranks may help the researcher in establishing concurrent validity of the test. Future research studies to convert it into a battery may help the professionals to screen and diagnose the hearing loss at early childhood. Further, Standardization of the USPT is also recommended by controlling the confounding variables like live voice, dialectal differences, verifying the normal hearing via objective tests, the concurrent validity, item analysis etc.

\section{CONCLUSION}

The Urdu Speech Perception Test is a non-verbal, reliable, and valid tool to assess analytic as well as synthetic auditory skill areas of children with hearing impairment in Urdu language. It can be used as a screening, diagnostic, and monitoring tool like other international speech perception tests that have been developed in recent years.

\section{DECLARATION OF INTEREST}

The authors report no declaration of interest.

\section{REFERENCES}

1. Boothroyd A. Measuring auditory speech-perception capacity in young children. In: Seewald RC, Bamford JM. A Sound Foundation through Early Amplification: Proceedings of the 3rd International Conference. Phonak AG; 2005,129-40.

2. Eisenberg LS, Martinez AS, Boothroyd A. Addressing auditory capabilities in young children. Int J Pediatr Otorhinolaryngol. 2005;71(9):1339-50. [PMID: 17604127] doi: 10.1016/j.jporl.2007.05.017

3. Kirk KI, Diefendorf AO, Pisoni, DB, Robbins AM. Research on Spoken Language Processing: Assessing Speech

Perception in Children (Report No 20). 1995. Indiana University.

4. Madell J. Pediatric amplification: Using speech perception to achieve best outcomes. AudiologyOnline. 2011;Article 841. Available at: http://www.audiologyonline.com. Accessed on Nov 17, 2012

5. Carhart R. Basic principles of speech audiometry. Acta Oto-laryngologica. Published online: 08 Jul 2009;62-71. Available at: http://dx.doi.org/10.3109/00016485109138908 
6. Zheng Y, Meng ZL, Wang K, Tao Y, Xu K, Soli SD. Development of the Mandarin early speech perception test: children with normal hearing and the effects of dialect exposure. Ear Hear. 2009;30(5):600-12.[PMID: 19726935] doi: 10.1097/AUD.0b013e3181b4aba8

7. Harris RW, Nissen SL, Pola MG, McPherson DL, Tavartkiladze GA, Eggett DL. Psychometrically equivalent Russian speech audiometry materials by male and female talkers: materiales de logoaudiometría en ruso psicométricamente equivalentes para hablantes masculinos y femeninos. Inter J Aud. 2007;46(1):47-66. [PMID: 17365055] doi: 10.1080/14992020601058117

8. Kishon-Rabin L, Rosenhouse J. Speech Perception Test for Arabic-Speaking Children: Prueba de perceptión del habla para niños hablantes del árabe. Inter J Aud. 2000;39(5):269-77. [PMID: 11093611] Available at: www.tandfonline.com/doi/pdf/10.3109/00206090009073091 Accessed on Oct 30, 2012.

9. Sagon R. The development of a phonetically balanced word recognition test in the llocano language [thesis]. Independent Studies and Capstones. Paper 382. Program in Audiology and Communication Sciences, Washington University School of Medicine. 2006. Available at: http://digitalcommons.wustl.edu/pacs_capstones/382. Accessed on Nov 21, 2016.

10. Dias MA, Devadas U, Rajashekhar B. Development of Speech Audiometry Material in Goan Konkani Language. Language in India. 2015;15(2):268-80. Available at: http://www.languageinindia.com/feb2015/ushakonkaniaudiometry.pdf. Accessed on Nov 19, 2016

11. Kumar SR, Mohanty P, Ujawane PA, Huzurbazar YR. Conventional speech identification test in Marathi for adults. Int J Otorhinolaryngol Head Neck Surg. 2016;2(4):205-15. doi: http://dx.doi.org/10.18203/issn.2454-5929.ijohns20163467

12. Kumar SR, Mohanty P. Speech Recognition Performance of Adults: A Proposal for a Battery for Telugu. Theory and Practice in Language Studies. 2012;2(2):193.Available at: https://pdfs.semanticscholar.org/8312/e6940b50ce34686d54283eb0d0cf84c2997b.pdf. Accessed on Nov 19, 2016.

13. Wyne N. Languages and their families-centre for Language Engineering. (n.d). Available at:www.cle.org.pk/Publication/Crulp_report/CR02_17E.pdf. Accessed on Nov 7, 2016.

14. Hussain S. Computational Linguistics (CL) in Pakistan: Issues and Proposals. 10th Conference of the European Chapter, 2003. p. 31. Retrieved from https://www.researchgate.net/profile/Petr_Sojka/publication/2868683 Context_Sensitive_Pattern_Based_Segmentation_A Thai_Challenge/links/09e415108b6e8af826000000.pdf\#page=40. Accessed on Nov 7, 2016.

15. Munthuli A, Tantibundhit C, Onsuwan C, Kosawat K. Methods and Tool for Constructing Phonetically-Balanced Materials for Speech Perception Testing: A Development of Thai Sentence-Length materials. 29th Pacific Asia Conference on Language, Information and Computation: Posters, Shanghai, China, October 30 - November 1, 2015, 293-301.

16. Saleem AM, Kabir HA, Riaz MK, Rafique MM, Khalid NA, Shahid SR. Urdu consonantal and vocalic sounds. Annual Student Report. Centre of Research in Urdu Lamguage Processing. 2002. Available at: http://www.cle.org.pk/Publication/Crulp_report/CR02_01E.pdf Accessed on Nov 7, 2016.

17. Martin FN, Champlin CA, Perez DD. The question of phonetic balance in word recognition testing. J Am Acad Audiol. 2000;11:489-93, quiz 522. [PMID: 11057733]

18. Erber NP. Auditory Training. Washington DC: AG Bell Association for the Deaf.1982.

19. Raza AA. Design and Development of an automatic speech recognition system for Urdu [Master's thesis]. FAST-National University of Computer and Emerging Sciences. 2009. Available at:

http://www.cle.org.pk/Publication/theses/2009/Automatic_Speech_Recognition_System_for_Urdu.pdf. Accessed on Nov 7, 2016.

20. Nawaz S. Deletion rules in Urdu language. Center for Research in Urdu Language Processing (CRULP), National University of Computer and Emerging Sciences, Lahore, Pakistan. 2002. Available at: www.crulp.org/research/reports/streports02.htm. Accessed on Jan 16, 2017.

21. Mahwish F, Benazir M. Urdu Phonological Rules in Connected Speech. Proceeding of the $6^{\text {th }}$ Conference on Language and Technology (CLT16). 2016,15-24. Available at: http://www.cle.org.pk/clt16/CLTProceedings.pdf

22. Khan I, Usman M, Shafi M, Ghani K, Minallah N. Towards an Efficient Urdu Keyboard Layout. Sindh University Research Journal-SURJ (Science Series). 2015;47(2). Available at: http://sujo.usindh.edu.pk/index.php/SURJ/article/view/821. Accessed on Nov 7, 2016.

23. Mukati AS. Identifying Core Vocabulary for Urdu Language Speakers Using Augmentative Alternative Communication. ProQuest LLC. 2013. Available at: http://search.proquest.com/docview/1466302513?pq-origsite=gscholar. Accessed on Nov 8, 2016.

24. Ali H, Ahmad N, Yahya KM, Farooq O. A medium vocabulary Urdu isolated words balanced corpus for automatic speech recognition. In Proceedings of 4th International Conference on Electronic Computer Technology, ICECT, Kanyakumari, India. 2012, 473-6. Available at: http://s3.amazonaws.com/academia.edu.documents/41134749/p-aliicect2012.pdf?AWSAccessKeyld=AKIAIWOWYYGZ2Y53UL3A\&Expires=1491392244\&Signature=GHP0Ys0IUeqTSrEu4A 
OYY\%2F6Kz8M\%3D\&response-content-

disposition=inline\%3B\%20filename\%3DA Medium_Vocabulary_Urdu_Isolated_Words.pdf. Accessed on Jan 16, 2017.

25. Silverman SB. Evaluation of the SPICE auditory training curriculum [thesis]. Independent Studies and Capstones. Paper 469. Program in Audiology and Communication Sciences, Washington University School of Medicine. 1996. Available at: http://digitalcommons.wustl.edu/cgi/viewcontent.cgi?article=1444\&context=pacs_capstones. Accessed on Feb 21, 2012.

26. Kinsey A. Psychometric Review of Language Tests for Preschool Children [thesis]. The Ohio State University. Department of Speech and Hearing Science. 2010. Available at:

https://kb.osu.edu/dspace/bitstream/handle/.../Abigail_Kinsey_Thesis.pdf. Accessed on Aug 23, 2013. 
Figure 1: It explains the frequency of occurrence of Urdu consonants in spoken language. It highlights the most frequently occurring consonants that should be given preference in auditory training lessons for the children with hearing impairment

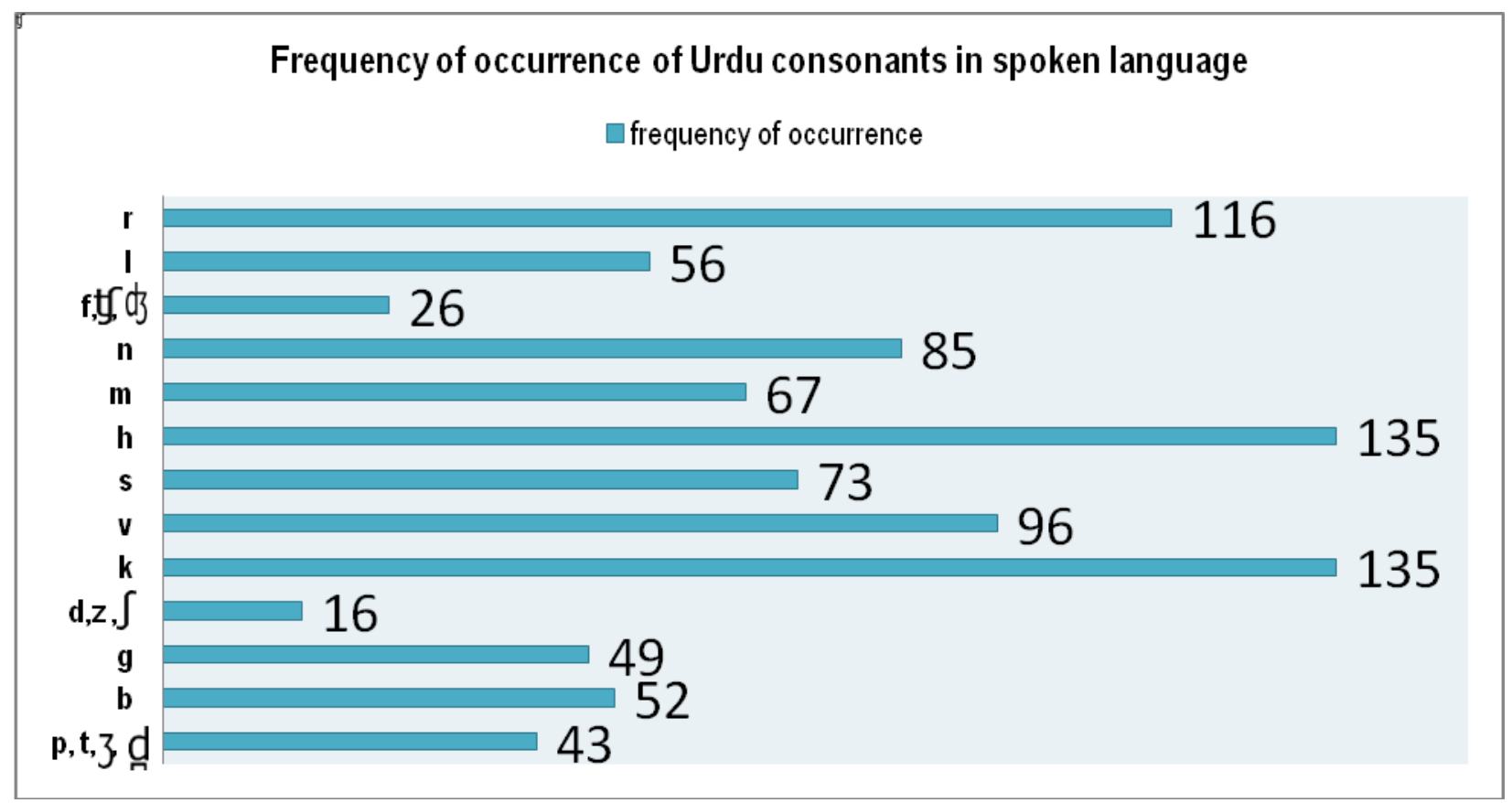


Figure 2: Evidence of predictive Validity of Urdu speech perception test is shown with the help of varying length of bars of the mean scores. Black colored bar represents mean scores of normally hearing subjects $(n=100)$ and grey colored bars represent mean scores of hearing impaired subjects. ( $n=10$ severly impaired subjects and 20 subjects with profound hearing loss).

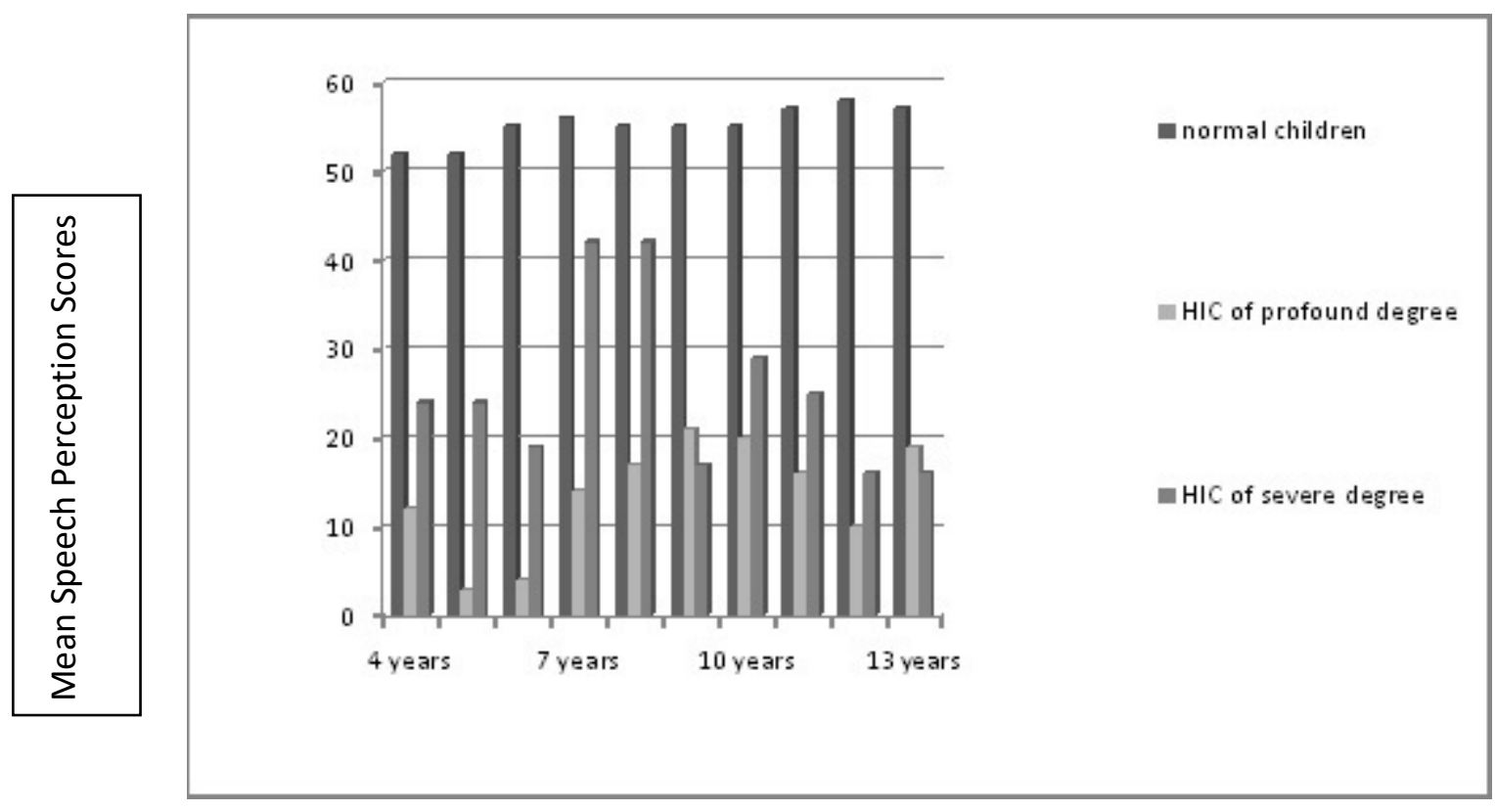


Figure 3: Evidence of the construct validity of Urdu speech perception test is shown with the help of slightly increasing slope of line graph of mean scores of normally hearing subjects in each age group. $n=100$.
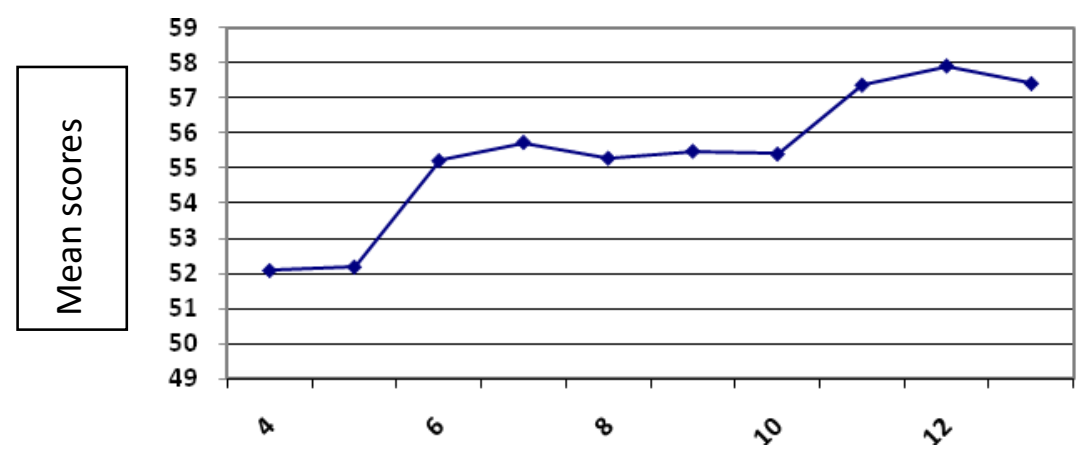

$\longrightarrow$ speech perception scores

Age in Years 